\title{
Lago Chad: qué se esconde tras la crisis de sus aguas
}

\section{Silvia Alejandra Perazzo*}

\section{RESUMEN}

El lago Chad es un oasis en medio del desierto. Se trata de un lago tropical cuya cuenca activa se alimenta principalmente de las aguas del río Chari y de su afluente el río Logone. Cerca de cien millones de habitantes viven de sus aguas. Desde hace varias décadas, su población atraviesa una situación de emergencia hídrica y humanitaria que es producto de una combinación de factores. Este artículo busca abordar esta problemática multidimensional desde la perspectiva hidrosocial que focaliza no solamente en las cuestiones ambientales, sino que considera que las crisis hídricas son resultado de las relaciones simbióticas entre el ser humano y la naturaleza. Esta perspectiva político-ecológica supone una estrecha relación entre las transformaciones en el ciclo hidrológico a nivel local, regional y global, de una parte, y las relaciones sociales, políticas, económicas y culturales de poder, de otra. Así considerado, las crisis involucran las estructuras estatales y las decisiones políticas, las geometrías de poder, las relaciones económicas y sociales de sus habitantes, y la relación que se establece entre estos factores y el medio ambiente. Por ello, este estudio no considera la cuestión del lago Chad como el mero resultado de un proceso natural de desertización o de cambio climático influenciado o no por la acción humana. Consideramos en cambio, que esta problemática está atravesada por múltiples variables y actores que interactúan y se influencian entre sí determinando la situación actual de la región, que en este caso, involucra además a cuatro estados africanos. Se utilizará asimismo el concepto de waterscape, entendiendo por ello "una unidad de paisaje", que es resultado de la interacción entre las sociedades y su ambiente.

En su expresión actual, el waterscape del lago Chad muestra una región que sufre desplazamientos humanos constantes debido a los cambios en el régimen de lluvias, la falta de aguas y de pasturas, resultantes de la desertización. A su vez, este movimiento de pueblos provoca conflictos comunales entre ganaderos y agricultores por la posesión y el uso de la tierra. La falta de legislación y de una gestión estatal que contemple una adecuada política de tierras agrava la violencia cotidiana que, por otra parte, también se ve exacerbada por la violencia estatal a la hora de reprimir los enfrentamientos comunales. Desde hace casi dos décadas, la región ha visto la proliferación de diversos grupos armados que encuentran en esta situación una ocasión propicia para desarrollar sus actividades ilícitas vinculadas al crimen organizado.

Teniendo en cuenta los lineamientos teóricos que hemos esbozado líneas arriba, en este artículo buscamos analizar la actual crisis del lago Chad como una crisis regional en la que se entremezclan factores ambientales, sociales y políticos. En este sentido, analizaremos la variación del régimen de lluvias y sus repercusiones sobre los estados del lago, los movimientos poblacionales históricos y actuales de las diversas etnias que habitan la región, el rol y las políticas impuestas para con habitantes por parte de los cuatro estados de la cuenca, la violencia estatal, comunal y terrorista que se verifica en la zona, y la vinculación entre estos factores como determinantes de la actual situación de la región.

\section{Palabras clave}

Ciclo hidrosocial; migraciones; terrorismo; pastores; agricultores; agua.

\section{TITLE}

Lake Chad: what is hidden behind the crisis of its waters

\section{Abstract}

Lake Chad is an oasis in the middle of the desert. It is a tropical lake whose active basin feeds largely on the waters of the Chari River and its main affluent, the Logone River. To a lesser extent, it receives contributions from the Komadougou Yobé, the Beid, the Yedseram and the Ngadda basins. The size of the lake is variable due to the

\section{DOl:}

https://doi.org//0.15366/relacionesinternacionales2020.45.012

Formato de citación recomendado:

PERAZZO, Silvia Alejandra (2020). “Lago Chad: qué se esconde tras la crisis de sus aguas”, Relaciones Internacionales, $n^{\circ} 45$, pp. 275-287.
* Silvia Alejandra PERAZZO,

Magíster en historia por la UNTREF (Argentina). Profesora Titular de

la Maestría de Relaciones Internacionales de USAL y Universidad Austral (Argentina), y de Historia de África en el I.S.P.“J.V.G”

(Argentina). Su línea de investigación es conflictos armados africanos. Presidente de ANU-AR y miembro del Comité de Asuntos Africanos de CARI. Contacto: silviaperazzo@anu-ar.orgu

Recibido:

03/05/2020

Aceptado: 06/07/2020 


\section{fluctuations in the rainfall regime.}

Nearly one hundred million inhabitants rely on its waters for food. For several decades, its population has been suffering a hydric and humanitarian crisis that is the result of a combination of various factors. The purpose of this paper is to address this multidimensional problem from a hydrosocial perspective, focusing not only on environmental issues but also considering that water crises are the consequence of symbiotic relationships between human beings and nature. This political-ecological perspective suggests, in Swyngedouw's words, a close correlation between the transformations of, and in, the hydrological cycle at local, regional and global levels on the one hand and relations of social, economic and cultural power on the other (2009, p. 56). Thus considered, crises involve state structures and political decisions, geometries of power, economic and social relations of its inhabitants, and the relationship established between these factors and the environment. Therefore, this study does not consider the Lake Chad issue as the mere result of a natural desertification process or as a consequence of climate change, influenced or not by human action. Instead, we consider that this issue comprises multiple variables and actors that interact and influence each other, thus shaping the current situation of the region, which also involves four African states. Additionally, we will use the concept of "waterscape" to refer to "a landscape unity" resulting from the interaction between societies and their environment, which involves, therefore, "all social, economic, cultural and political processes through which nature is perceived and transformed by societies, as well as - in return - the influence of these environmental changes on societies" (Molle, 20I2, p.220). In its current form, Lake Chad's waterscape shows a region suffering constant human displacements and insecurity due to the conflicts triggered by human migrations in search of new lands as a consequence of the desertification caused by changes in rainfall levels. These displacements are, in turn, influenced and aggravated by state action and state violence, and by the proliferation of various armed movements that leverage the situation to pursue their illicit activities linked to organized crime.

The Lake Chad Basin is part of a circuit of trade routes established centuries ago by populations largely dependent on livestock and agriculture, who experienced periods of peaceful coexistence among them, and others not so peaceful. In modern times, this modus vivendi has been disrupted by droughts and desertification. Consequently, populations have moved from the most arid to the most humid regions, while confrontations between semi-nomadic populations or herders and sedentary populations have proliferated. In the basin states, these displacements soon led to violent clashes between herders and farmers over land use and access to water sources.

In view of such a scenario, states have not acted effectively in order to stop violence. Since their independence, the Sahelian states have neglected the desert regions of their territories mainly because of the resistance of their inhabitants to bureaucratic state practices that affected their nomadic or semi-nomadic way of life. This is the reason why such regions never had access to the basic services or economic possibilities that were available at urban centers. Consequently, desert regions did not have access to health, education, basic health services or even safe drinking water.

States have also failed to implement a land policy that ensures access to the resources that each sector needs in order to survive and prosper.The legal gaps regarding land tenure and the coexistence of several "legal categories" (such as reserves, communal land, vacant land, etc.) is a pervasive reality in this region, which reveals traditional coexistence mechanisms that are not in line with states' bureaucratic dynamics, sometimes clashing with them.

The Lake Chad Basin states have not either been able to bring an end to the terrorist violence unleashed mainly by Boko Haram and Islamic State in West Africa Province (ISWAP). As a matter of fact, one of the main strategies for recruiting members and getting civilian support in the early days of Boko Haram had to do with the provision of basic health services and the opening of Koranic schools, trying to fill the gaps left by an absent state. Subsequently, Boko Haram resorted to forced recruitment, looting and widespread violence against the inhabitants of the cities and towns where it settled.

The states' military response was channeled through the Multinational Joint Task Force (MNJTF) and various national or bilateral operations in the affected states. The MNJTF organized several boisterous operations -some of them successful, and others not so much- but managed to significantly reduce Boko Haram's area of influence.

Taking the hydrosocial perspective into account, this paper seeks to analyze the variation in the rainfall level and its impact on the lake's conditions; the historical and current population movements of the various ethnic groups inhabiting the region; the role of the region's inhabitants and the policies imposed on them by the four basin states; the state, communal and terrorist violence occurring in the area; and the link among these factors as determinants of the current regional crisis.

\section{KEYWORDS}

Hydrosocial cycle; migrations; terrorism; herders; farmers; water. 


\title{
ntroducción
}

La cuenca del lago Chad es un oasis en medio del desierto. Desde hace varias décadas, la región ha experimentado un importante crecimiento demográfico y movimientos poblacionales de diversa índole, lo que sumado al descenso en el régimen de lluvias ha llevado a quienes habitan la cuenca a una situación de emergencia hídrica y sanitaria.

Encarar las cuestiones hídricas desde una perspectiva "hidrosocial" implica abordar las problemáticas del agua superando la tradicional visión dual que divide su ciclo hidrológico del accionar humano y político sobre ella. Por el contrario, se considera al hombre inmerso, en convivencia y en interacción con la naturaleza.

\begin{abstract}
"En un intento sostenido por trascender la oposición modernista naturaleza-sociedad, la investigación hidrosocial considera la circulación del agua como un proceso físico y social, como un flujo socio-natural hibridado que fusiona de manera inseparable la naturaleza y la sociedad /.../. Plantea una revisión de los enfoques tradicionales fragmentados e interdisciplinarios sobre el estudio del agua insistiendo en la inseparabilidad de lo social y lo físico en la producción de configuraciones hidrosociales específicas" (Swyngedouw, 2009, p. 56).
\end{abstract}

De esta forma,"'los ambientes producidos son resultados históricos específicos a partir de procesos socio-biofísicos” (Swyngedouw, 2009, p. 56). Tal como apunta Larsimon —apoyándose en diversos autores-, el ciclo hidrosocial, opuesto al uso convencional del ciclo hidrológico "natural" que prosigue eternamente independientemente de la actividad humana, concibe y analiza "la naturaleza socio-ecológica del agua, reconociendo que los procesos hidrológicos son moldeados por las actividades e instituciones humanas, [y] que los datos y conocimientos hidrológicos son construidos de manera subjetiva" (2014, p. 4). Por ende, "los procesos de cambio socioambiental nunca son social o ecológicamente neutrales. Se crean así condiciones en las que ciertas trayectorias de cambio socioambiental socavan la estabilidad o la coherencia de algunos grupos o ambientes sociales" (Swyngedouw, 2009, p. 57).

“[...]el estudio político-ecológico del proceso hidrosocial revela la naturaleza intrínsecamente conflictiva del proceso de cambio socioambiental y saca a la luz los conflictos inevitables (o sus desplazamientos) que impregnan el cambio socioambiental. Por consiguiente, es necesario prestar especial atención a las relaciones sociales de poder (sean materiales, económicas, políticas o culturales) a través de las cuales se producen las transformaciones hidrosociales. Ello implica también el análisis de los discursos y los argumentos que se utilizan para defender o legitimar determinadas estrategias. Son esas geometrías de poder y los actores sociales que las llevan a cabo los que, en última instancia, deciden quiénes 
tendrán el acceso o el control de los recursos o de otros componentes del ambiente y quiénes serán excluidos de ese acceso o control." (Swyngedouw, 2009, p.57).

Así las cosas, este estudio no considera la cuestión del lago Chad como el mero resultado de un proceso natural de desertización o de cambio climático influenciado o no por la acción humana. Consideramos que esta problemática está atravesada por múltiples variables y actores que interactúan y se influencian entre sí, determinando la situación actual de la región, que, en este caso, involucra además a cuatro estados africanos. Por otra parte, estas "creaciones coloniales que buscan volverse naciones coherentes" (Ki-Zerbo, Mazrui y Wondji, 1993, p. 435) fueron concebidas como "estados nación", pero son en realidad estados plurinacionales o pluriétnicos en los que no siempre todas las naciones, etnias o pueblos están representados.

En suma, analizaremos la región del lago Chad, teniendo en cuenta el concepto de waterscape. Entendemos por ello, "una unidad de paisaje", expresión de la interacción entre las sociedades y su ambiente; comprende, por lo tanto, "todos los procesos sociales, económicos, culturales y políticos a través de los cuales la naturaleza es percibida y transformada por las sociedades, así como, en contrapartida, la influencia de estos cambios medioambientales sobre las sociedades" (Molle, 20I2, p. 220).

La expresión actual de este proceso interrelacional, el waterscape del lago Chad, es una región que sufre desplazamientos humanos constantes e inseguridad debido a los conflictos que provoca el movimiento de pueblos en busca de nuevas tierras por la desertización resultante de los cambios en el régimen de lluvias; estos movimientos son, a su vez, influenciados y agravados por la acción estatal y la violencia del estado a lo que se suma la proliferación de diversos movimientos armados que ven en la situación una ocasión propicia que favorece sus actividades ilícitas vinculadas al crimen organizado.

\section{Delineando el waterscape del lago Chad}

El lago Chad es un lago tropical cuya cuenca activa se alimenta principalmente de las aguas del río Chari y de su afluente el río Logone; en menor medida, recibe aportes de la cuenca del Komadougou Yobé, el Beid, el Yedseram y el Ngadda'. El tamaño del lago es variable debido a las fluctuaciones en el régimen de lluvias, sobre todo en la cuenca del Chari: la superficie media de agua del lago es, en efecto, aproximadamente proporcional a las pérdidas anuales de este río (Lemoalle, 20I4, p. 25).

La cuenca del lago está situada en la Zona de Convergencia Intertropical (ZCIT) donde se encuentran el anticiclón de las Azores y el Anticiclón de Santa Helena. Es al sur del máximo de esta zona de convergencia donde se desencadenan las lluvias más abundantes. La ZCIT se desplaza hacia el norte de enero a julio y vuelve al sur de julio a enero. La cantidad de lluvias y la duración de la estación lluviosa dependen de la amplitud de movimiento de la zona de convergencia, que puede variar notablemente (Lemoalle, 20 I4, p. 20). Lo que influye en el desplazamiento de la zona

La cuenca oro-hidrográfica del lago Chad tiene una superficie de $2.400 .000 \mathrm{~km}$ cuadrados, el $8 \%$ del continente africano, constituyendo antiguamente la cuenca del Mega Lago Chad. (Lemoalle, 2014, p. 19) 
de convergencia es el Frente Intertropical (FIT), confluencia de los vientos alisios cálidos y extremadamente secos denominados Harmattan y los alisios provenientes de Guinea menos cálidos y más húmedos. En el Sahel, el pasaje del FIT presagia la estación lluviosa. Sin embargo, el pasaje del Frente no es regular como el monzón indiano, lo que determina una variabilidad interanual de lluvias muy acentuada. Estos fenómenos atmosféricos provocan a nivel suelo un descenso de la importancia y duración de las lluvias en dirección sur-norte, el aumento de temperaturas y la consiguiente evaporación producto de ellas (Lemoalle, 20I4, p. 2 I).

Estos mismos fenómenos, inciden sustancialmente en el caudal del río Chari, de allí el descenso o no de sus aguas y la modificación de su paisaje. En consecuencia, el lago Chad presenta aspectos diferentes que pueden resumirse en cuatro estados principales:

- Gran lago Chad: caracterizado por una superficie de agua libre de aproximadamente 24.000 $\mathrm{km}^{2}$, rodeado de un archipiélago dunario poco desarrollado. El estado de "Gran Chad" fue característico de la década de los cincuenta.

- Estado Chad Medio: presenta una superficie entre 15.000 y $24.000 \mathrm{~km}^{2}$, caracterizado por grandes extensiones de agua libre navegable, multiplicidad de islas y vegetación a lo largo de sus orillas. Pueden distinguirse una cuenca norte y otra sur unidas mediante un estrangulamiento del terreno. Desde mediados de la década de los cincuenta hasta 1972, el lago presentó este estado. Sin embargo, durante el siglo XX, la Fase Mediano Chad fue interrumpida varias veces por el estado Pequeño Chad, lo que demuestra la variabilidad de las alteraciones climáticas.

- Pequeño Chad: este estado, en el que se encuentra el lago desde la década de los setenta, se caracteriza por diversos planos de agua separados durante al menos una parte del año. La característica más importante radica en la división del lago en dos cuencas, una sur y otra norte separadas por la emergencia de una Gran Barrera vegetal que no llega a ser cubierta por el importante descenso de las aguas. Pantanos permanentes o estacionarios pueden encontrarse a lo largo del lago cuya extensión de aguas libres oscila entre los 2000 y 14.000 $\mathrm{km}^{2}$. En períodos de Pequeño Chad Seco, la cuenca norte puede inclusive quedar totalmente seca tal como ocurrió en 1985, 1987, 1988 y $\left.199\right|^{2}$ (Lemoalle, 2014, p. 25, pp. 32-37).

Los estados del lago influyen, condicionan y hasta determinan toda la vida cotidiana de los más de 100 millones de personas que viven de sus aguas. Por otra parte, los cambios de tamaño del lago también ayudan a comprender el testimonio de esta trabajadora humanitaria que intentaba buscar a las víctimas de los ataques de Boko Haram con mapas de treinta años atrás: "Todos nuestros mapas eran erróneos, porque eran de la década del setenta-noventa. Estábamos manejando a través de áreas que deberían haber estado bajo las aguas, pero no podíamos ver el lago" (The Yorker, 2017) ${ }^{3}$.

Más aun, el lago Chad ha permanecido en el estado Pequeño Chad el 69\% del tiempo entre 1957 y la actualidad, y la cuenca norte ha permanecido seca al menos una parte de los años 1975, 1977, 1982, 1984, 1990, 1992, 1993 y 1994. Conservó al menos un poco de agua todo el año desde 1995 hasta 2013. (Lemoalle, 20I4, p. 37).

3 La variabilidad en el régimen de lluvias coloca un manto de duda sobre si la situación del lago obedece a este régimen o tiene que ver con el cambio climático. De hecho, varios autores lo consideran como un mito.Véase nota 10. 
Convencionalmente, la cuenca del Chad está integrada por los estados de Nigeria, Chad, Camerún y Níger, firmantes todos de la Convención de Fort Lamy (hoy, Yamena) y sus dos estatutos en 1964, los que dieran origen a la Comisión de la Cuenca del Chad (LCBC, por su sigla en inglés). Originariamente, la cuenca convencional del lago cubría una superficie de $427.300 \mathrm{~km}^{2}$; hoy, cubre más del doble, $967.000 \mathrm{~km}^{2}$, por haberse sumado a la Convención la República Centroafricana ${ }^{4}$.

Como en casi toda África, las fronteras de los estados fueron determinadas por la Conferencia de Berlín (1884-1885) y los sucesivos tratados bilaterales y multilaterales entre países europeos como consecuencia de ella. Por la Convención Germano-Británica de 1893 y la Convención del Níger de 1898, la cuenca se dividió en tres administraciones: francesa, alemana y británica. Para su delimitación, se tomaron como referencias datos de latitud y longitud ${ }^{5}$ y la premisa de que todas las administraciones tuvieran acceso a las aguas del lago; los pueblos que allí vivían fueron divididos según estas delimitaciones foráneas y arbitrarias que nunca tuvieron en cuenta ni las formaciones políticas preexistentes, ni la distribución regional de grupos nacionales o etnias, ni las diversas formas de vida que estos pueblos tenían ${ }^{6}$.

Con el advenimiento de las independencias africanas, la aplicación del principio del uti possidetis, avalado posteriormente por la Organización para la Unidad Africana (OUA), transformó las fronteras de las antiguas administraciones coloniales en las fronteras de los nuevos estados. Así, la administración del lago Chad recayó en Nigeria (ex administración británica), en Níger y Chad (pertenecientes al África Occidental y Ecuatorial Francesa, respectivamente) y Camerún (primero alemana y luego África Ecuatorial francesa).

Ahora bien, decenas de pueblos habitan la cuenca del lago Chad, muchos de los cuales hacen caso omiso de las fronteras impuestas y se manejan en cambio siguiendo lazos culturales, étnicos o intereses económicos ${ }^{7}$. Los movimientos de pueblos a lo largo de su historia han dado lugar a poblados, ciudades y asentamientos —algunos permanentes y otros estacionales - que se diseminan por toda la cuenca. La multiplicidad de orígenes y etnias es un rasgo dominante de todos ellos. De esta forma, pueden encontrarse mayoritariamente poblaciones de origen hausa, yoruba, fula, kanuri, manga, mobber, árabes, massa, kalabaye, igbo, kotoko, entre decenas de otros, a quienes se suman poblaciones procedentes de República Centroafricana, del este de Chad y de diversas regiones de África Occidental. En este escenario, es de imaginarse cómo los cambios de estado del lago provocan nuevos desplazamientos y nuevas migraciones en busca de sustento para sus actividades favoreciendo además, otros nuevos asentamientos más o menos permanentes.

En la actualidad, estos movimientos se producen sobre todo hacia la cuenca sur del lago por razones múltiples. En primer lugar, porque hasta ahora no se ha desecado — como sí ha ocur-

\footnotetext{
La Cuenca convencional del lago no debe confundirse con la Cuenca hidrográfica que posee $2.335 .000 \mathrm{~km}^{2}$ y que incluye a Libia y República Centroafricana (Cfr. Moritz, 2005, p. 98).

$13^{\circ} 5$ de latitud norte y $14^{\circ} 5$ de longitud este para la frontera tripartita.

Estos límites fueron revisados luego de la Primera Guerra Mundial por el tratado Milner-Simon de 1919, que corrió hacia el este la frontera entre Nigeria y Camerún acorde a la reorganización colonial de la Sociedad de las Naciones, que excluyó a Alemania de África.

7 Mientras que los estados ribereños se disputan la posesión de ciertas partes del lago Chad, las comunidades de pastores, pescadores, agricultores de diferentes nacionalidades se entremezclan e interactúan sin preocuparse por las fronteras. Más allá de que los desplazamientos humanos estén regidos por las normas de las migraciones internacionales en la región, las fronteras son extremadamente porosas (Réounodji et al., 2014, p.153)
} 
rido con la cuenca norte- y porque hay continua actividad económica vinculada al abastecimiento de ciudades importantes, como por ejemplo la ciudad nigeriana de Maidiguri.Vinculado a esto último, la cuenca sur también recibe gran cantidad de migrantes y desplazados producto de las variaciones climáticas en otras regiones del Sahel ${ }^{8}$ pertenecientes al norte de Nigeria, sur de Níger y sudeste de Chad. En tercer lugar, a la región llegan poblaciones que huyen de políticas represivas estatales —en Chad, por ejemplo_-, de la violencia desatada por grupos armados — como Boko Haram e ISWAP - y de diversos conflictos armados regionales - República Centroafricana, Libia, entre otros-

En este contexto, son frecuentes los enfrentamientos entre los que llegan y los que están, lo que a su vez desata nuevos desplazamientos y consecuentemente nuevos asentamientos. Un ejemplo de ello pueden ser los choques entre pastores y agricultores ${ }^{9}$, de diversas etnias y nacionalidades y que se producen fuera y dentro de la cuenca del lago.

Los constantes movimientos de población y los índices de crecimiento demográfico que se encuentran entre los más altos del planeta provocan una presión sobre las aguas del lago Chad que no puede ser soportada independientemente del estado actual en que se encuentra ${ }^{10}$.

Por lo que hemos esbozado en estas líneas, consideramos que es más exacto considerar la cuenca del Chad como lugar no delimitado por fronteras nacionales —aunque estas existan-, sino como una región donde confluyen diversos pueblos con actividades económicas, costumbres y religiones diferentes, que viven de las aguas del lago, con procesos de relacionamiento preexistentes a las actuales construcciones estatales y a sus límites fronterizos, y que, a su vez, se ven atravesados por las políticas de los estados surgidos luego del proceso de descolonización y por redes del crimen transnacional organizado, como se analizará más adelante. Es esta nuestra delimitación del waterscape del lago Chad. Es también esta situación la que provoca que los sucesos a un lado de la frontera repercutan casi en forma instantánea en el estado vecino.

\section{Explorando el waterscape}

La cuenca del Chad forma parte de un circuito de rutas establecidas desde hace siglos entre las poblaciones ganaderas y agricultoras, que conocieron largos períodos de convivencia armónica entre ellos y otros no tanto. En tiempos actuales, este modus vivendi fue alterado por las sequías y la desertización; como consecuencia, se produjeron desplazamientos de población desde las regiones más áridas hacia las más húmedas, a la vez que proliferaron los enfrentamientos entre poblaciones semi nómadas o pastoriles y las poblaciones sedentarias.

8 Por ejemplo, las regiones sahelianas de Guera, Batha y Ouaddai. (Réounodji et al., 20 I4, pp. I53 y I59).

En este trabajo, cuando nos referimos a pastores estamos señalando a integrantes de diversas etnias, poseedores de ganado que practican el semi nomadismo o el nomadismo estacional. Con agricultores, nos referimos, en forma genérica, a integrantes de poblaciones sedentarias poseedores de tierras a pequeña o gran escala, incluyendo también a los granjeros.

10 Diversos autores que hemos consultado -como Lamoalle y Magrin-sostienen que la reducción del volumen de agua de lago se debe a la variabilidad del régimen de lluvias, especialmente al descenso de los aportes del río Chari. No consideran que sea efecto del cambio climático ni que esté en proceso de desaparecer. Por otra parte, y mediante el trabajo con modelos, intentan demostrar que la actual situación del lago Chad no se debe solamente al descenso de las aguas y todo lo que esto significa cultural y económicamente, sino que se debe a la presión demográfica que soporta. Concluyen que, con los niveles del lago en 1960, tampoco se hubiera podido soportar la presión demográfica actual. 
En Nigeria, por ejemplo, las rutas tradicionales indican que los ganaderos nómadas, mayoritariamente fula", descendían hacia el centro y el este de Nigeria entre los meses de octubre y mayo. Con el proceso de desertización ${ }^{12}$, las estadías fueron mucho más prologadas y hasta determinaron la permanencia definitiva en las zonas húmedas de muchos de estos grupos que antes se instalaban estacionalmente. El consecuente aumento de presión sobre las tierras y el agua disponibles y la competencia por estos recursos ahondaron las diferencias étnicas y religiosas entre los fula musulmanes y las poblaciones sedentarias integradas por decenas de pueblos cristianos o que profesaban religiones tradicionales africanas.

Desde hace casi dos décadas, en la región central de Nigeria, también conocida como Middle Belt, las diferencias se tradujeron en enfrentamientos violentos que se incrementaron exponencialmente desde 2015, llegando a registrar más víctimas que las producidas por Boko Ha$\mathrm{ram}^{13}$. A su vez, desde hace varios años, proliferaron grupos de autodefensa de agricultores y granjeros, por un lado, y de pastores nómadas, por otro, que actúan al margen del estado. En un principio, las acciones de autodefensa fueron respuestas violentas aisladas y venganzas personales para luego transformarse en verdaderos ataques orquestados contra poblados completos. Estos grupos de autodefensa generan, asimismo, acciones de represalia y espirales de violencia ${ }^{14}$ y hasta se benefician del amplio comercio de armas ilícitas que se desarrolla en el país ${ }^{15}$. Por otra parte, frecuentemente también extorsionan a los pobladores pidiendo dádivas y diversas prebendas a cambio de protección.

Las respuestas estatales incluyeron desde la solución militar para reinstalar el orden hasta la propuesta de leyes consensuadas tanto con los pastores como con los agricultores. Hasta el presente, han sido insuficientes $y$ en ocasiones aumentaron los niveles de violencia, mientras que ambos bandos se quejan de la falta de justicia y de castigo a los responsables de la violencia.

Los desplazamientos de pastores fula no quedaron restringidos a Nigeria, sino que se expandieron por toda la cuenca del Chad donde, a su vez, también se produjeron movimientos poblacionales importantes de esta y otras etnias por motivos similares. En el norte de Camerún, la utilización de la tierra y el acceso al agua opone actualmente a los Arabes Choa (pastores) y a los Kotoko (agricultores) y a los fula (pastores) y Kanouri (agricultores) (Réounodji et al., 20 I4, p. I59).

En Chad, el enfrentamiento entre pastores y agricultores en las provincias del este del país llevaron al gobernador de la provincia de Chari a declarar el estado de emergencia, en agosto

"Fula, fulani, FulBe, peul hacen siempre referencia a la misma etnia, que posee decenas de líneas internas.

12 Según la Agencia Nacional Meteorológica (2008), la estación lluviosa en el norte de Nigeria descendió de I50 a I20 días en los últimos 30 años.Y en las últimas décadas, se produjo un avance de las zonas desérticas hacia el sur a razón de 0,6 m por año (Cfr. ICG, 20I7, p. 3).

13 Tan solo en 2016, se registraron más de 2069 muertos en las provincias de Benué y Kaduna, mientras que el número de desplazados llegaba a 62.000 en la región de Benué; paralelamente, se reportaron intimidaciones a poblaciones de agricultores y decenas de secuestros, violaciones y ataques hacia mujeres y niñas por parte de los pastores (ACAPS, 20I7, pP. I-2). En 20I7, fueron más de 500 los muertos por enfrentamientos en la región (Cfr. El País, 25 de junio 2018) y más de 1300 hasta agosto de 2018 (Cfr. Human Rights Watch, 20I8).

14 A finales de diciembre de 2017, una milicia de jóvenes Bachama (grupo étnico agricultor y cristiano) atacó tres asentamientos de pastores (Shaforon, Kikem y Kodemti), matando a 55 personas, incluyendo a 48 chicos. El ataque desencadenó represalias en cinco pueblos Bachama por parte de los fula, con un centenar más de nuevas víctimas. Los ataques entre ambos grupos continuaron durante todo enero de 2018 (Cfr. ICG, 2018, p. 3). La violencia se extendió durante casi todo 2018 , siendo uno de los casos más dramáticos los choques sucedidos en la provincia de Plateau de agosto de 2018, donde las víctimas superaron las 200 muertes según fuentes oficiales.

15 Muchos de los integrantes de las milicias tienen rifles de asalto incluidas las AK47; algunos altos mandos militares nigerianos sostienen que estos grupos de autodefensa están mejor armados que el ejército regular (Cfr. ICG, 2018, p. 5). 
de 2018. En las regiones sahelianas de Batha, de Chari-Baguitmi y de Barh El Ghazal, se oponen diversas facciones árabes - criadores de vacas y de dromedarios - en torno a los pozos de agua. Para evitar estos enfrentamientos a menudo mortales, la búsqueda de agua conduce a facciones árabes y peul hacia el lago Chad (Réounodji et al., 20I4, pp. I53-I54). Una situación parecida puede describirse en Níger donde los peulm, dollo, dosso, hawsa y kanouri (estos últimos provenientes de Nigeria) también se volcaron a las orillas del lago (Réounodji et al., 2014, pp. I53-I54) ${ }^{16}$.

En este sentido, podríamos decir que muchos de los conflictos pastorales que se dan en el interior de los estados que conforman la cuenca del Chad repercuten en el ecosistema social del lago, de por sí ya complejizado por los procesos de desecamiento y el crecimiento demográfico. Esto se ve, a su vez, agravado por las solidaridades étnicas, las fronteras porosas y la falta de una adecuada respuesta estatal.

En este contexto de enfrentamientos comunales, el bandidismo es moneda corriente en toda la cuenca y territorios aledaños. El robo de ganado y el abigeato es un delito constante que afecta tanto a los pastores nómadas como a las poblaciones sedentarias. Muchas veces, los salteadores roban y asesinan en un estado y se refugian en otro. Esta nueva muestra de fronteras porosas, dificulta la finalización de estas actividades delictivas por los diversos sistemas de policía, de administración y de justicia que imperan en los diversos estados. Y esto sin considerar las ocasiones en la que los bandidos saben que conseguirán el amparo oficial en un Estado por su rivalidad con el otro.

Frente al problema intercomunal, los estados no han logrado actuar eficazmente para frenar la violencia. Desde la independencia, los estados sahelianos han descuidado las regiones desérticas de sus territorios, sobre todo por la resistencia de sus habitantes a aceptar las prácticas burocráticas estatales que afectaban su estilo de vida nómada o semi nómada ${ }^{17}$. La presencia del estado modificó la forma de vida de estas poblaciones mientras paralelamente las abandonaba a su suerte sin proveer servicios básicos ni posibilidades económicas con las que contaban los centros urbanos. Así, se les negó hasta la actualidad el acceso a la salud, a la educación, a servicios sanitarios básicos y hasta al agua potable.

Los estados también han fallado en implementar una política de tierras que asegure a cada sector los recursos necesarios para subsistir y prosperar. Las lagunas jurídicas respecto a la tenencia de la tierra y la coexistencia de diversos "status jurídicos" de las mismas (reservas, tierras comunales, tierras vacantes, etc.) es una realidad presente en esta región, que revela mecanismos de convivencia tradicionales que se acoplan mal a las dinámicas burocráticas de los estados y a veces chocan con ellas. Camerun es un buen ejemplo de ello.

A su vez, faltan legislaciones adecuadas para regular el uso de pasturas, reservas, tierras comunales y tierras reservadas a las actividades agrícolas privadas. En Nigeria, por ejemplo, los pastores perdieron gran parte de las reservas donde podían alimentar el ganado por legislaciones

\footnotetext{
16 Esta situación de violencia también es posible por la gran disponibilidad de armas que pueden conseguirse en el mercado negro como consecuencia del proceso de desintegración estatal de Libia y otros conflictos regionales.

17 Por ejemplo, los impuestos y tasas que eran percibidos por ellos en prácticas consuetudinarias y que ahora pasaban a estar centralizadas y usufructuadas por el estado, las restricciones al movimiento, la necesidad de documentación, etc.
} 
restrictivas, cambios en las estructuras administrativas y falta de medidas para evitar el avance privado (ICG, 20I7, p. 4). Contrariamente, hubo programas estatales para favorecer las granjas y las actividades agrícolas, lo que fue visto como discrecional por parte de los pastores. Frente al espiral de violencia intercomunal, el estado respondió con leyes que prácticamente prohibían el pastoreo y obligaban a los ganaderos a adquirir tierras en el corto plazo para alimentar su ganado ${ }^{18}$.

La cuestión estatal también es más profunda. Las características neopatrimoniales que estos estados presentan hacen del ejercicio del poder un negocio privado. En este contexto, la corrupción es moneda corriente en todos los niveles administrativos estatales. En sus tratos informales con los ganaderos nómadas, los agentes del estado, mediante "procedimientos informales", usan el sistema burocrático y sus leyes, políticas y presupuestos — por ejemplo, los programas de vacunación, permisos de trashumancia, impuestos a la trashumancia, documentos personales, aduanas - para obtener dádivas y prebendas por parte de ellos. Tal es el caso que se verifica con los FulBe en la región norte de Camerún, donde los oficiales de aduana, recaudadores de impuestos, gendarmes y policía utilizan la violencia y la amenaza de la violencia para extorsionar a pastores sin papeles, pero con ganado y dinero (Moritz, 2005, p. 94).

Como ya hemos afirmado, el estado en sí mismo — y más aún en su forma neopatrimonial ${ }^{19}$ fue disruptivo de las formas de vida tradicionales; también alteró las formas de resolución de controversias que antes se dirimían a nivel local y que, con el avance de la burocratización, vieron intervenir e interferir a nuevos actores, como la policía, la justicia, los gobernadores. Estos agentes del gobierno tienen en los conflictos locales una buena fuente de ingresos personales, los que por la misma razón siempre dilatan su solución. Como consigna ICG para el caso nigeriano, los pastores odian estas nuevas instituciones, pues la policía corrupta se lleva dádivas y prebendas mientras con extraños y largos procesos judiciales inmovilizan el ganado. Asimismo, los políticos locales tienden a favorecer a los agricultores sedentarios cuyos votos necesitan, mientras que los pastores, con su ganado itinerante, quizás no contarán para ellas; consecuentemente, los pastores se sienten totalmente marginados a la vez que desconfían de los líderes políticos locales como mediadores en el conflicto (IGC, 2008, p. I2). Toda la situación redunda en una mayor desconfianza hacia el estado por parte de las poblaciones afectadas por la violencia.

Los estados de la cuenca del lago Chad tampoco han podido terminar con la violencia terrorista desatada sobre todo por Boko Haram e Islamic State in West Africa Province (ISWAP). Antes de la instalación de estos grupos, la región ya poseía enormes niveles de inseguridad. Operaban allí redes del crimen organizado mientras el contrabando, que incluía desde productos de primera necesidad hasta cigarrillos, vehículos, medicamentos, armas pequeñas y ligeras y drogas, era moneda corriente, al igual que el bandidismo. Todo esto fue favorecido por la casi ausencia del estado y la corrupción de los agentes gubernamentales, lo que a su vez posibilitó que la región haya sido santuario para terroristas y criminales internacionales de todo tipo ${ }^{20}$ (Mahmood y Ani, 2018, pp. 6-7).

18 Véase la Open Grazing Prohibition and Ranches Establishment Law of 2017 government of Benue State, de Nigeria.

19 Entendemos por esto aquellos estados que son solo fachadas vacías detrás de la cual se esconden los negocios personales de quienes lo detentan a través de redes de clientelismo. La burocracia estatal usa los dineros públicos para su propio beneficio y el de sus clientes (Moritz, 2005, p. 84)

20 Por ejemplo, aquí encontraron asilo los miembros de del Movimiento para la Democracia y la Justicia (MDJ) que tuvo en jaque al gobierno de Chad durante los 90 (IGC, 2008, p. I2). 
El mismo abandono estatal sumado a la porosidad de las fronteras colaboraron para la instalación del terrorismo. Precisamente, una de las principales fuentes de reclutamiento de adeptos y de apoyo civil en los comienzos de Boko Haram tuvo que ver con la provisión de servicios sanitarios básicos y la apertura de escuelas coránicas, aprovechando los huecos de un estado ausente. La desconfianza hacia el estado y la corrupción de los agentes estatales también colaboró para ese apoyo inicial. Posteriormente, Boko Haram recurrió al reclutamiento forzado, al saqueo y la violencia generalizada hacia los habitantes de las ciudades y poblados donde se instalaban ${ }^{21}$.

Boko Haram ha amenazado el norte y nordeste de Nigeria con centenares de acciones armadas desde el 2009, aunque sus orígenes se remonten a su creación en 2002. Desde estas regiones, las dos facciones en que se dividió el movimiento han expandido su influencia hacia Níger, Chad y el norte de Camerún. Ya antes de alcanzar la zona del lago, la sola presencia del grupo terrorista había afectado gravemente las redes comerciales que vinculaban a sus habitantes con los principales centros de abastecimiento y comercio.

Luego de proclamar su intención de instalar un califato islámico hacia 2014, Boko Haram comenzó a desplazarse hacia la región del lago Chad, aterrorizando a la población, que nuevamente buscó en el desplazamiento la solución a la inseguridad. Por su parte, el ISWAP, facción disidente de Boko Haram, también logró alcanzar la zona del lago Chad atrincherándose en la localidad de Nguigmi (Níger).

Miles de habitantes de las islas del lago corrieron hacia el campamento de refugiados de Dar es Salam y otros tuvieron que abandonar sus casa obligadamente por orden de los gobiernos de Chad, Níger y Nigeria ${ }^{22}$. Los pobladores fueron atrapados tanto por la violencia terrorista como por la violencia estatal, agravando la desesperación y el abandono de estas poblaciones.

ISWAP es una facción de Boko Haram que prioriza la política a la acción armada. Si bien avanza por la fuerza, no suele ejercer violencia sobre sus habitantes, no recurre al reclutamiento forzoso, ni al matrimonio forzado para las mujeres, sino que les permite seguir con su vida cotidiana, asegura el comercio y las actividades económicas e, inclusive, les permite a quienes los deseen abandonar el lugar a cambio de un impuesto. Su objetivo es lograr ser una alternativa al Estado nigeriano, promoviendo un modelo estatal que utilice la ley sharia y que, a la vez, asegure el bienestar de sus habitantes. En los lugares donde logró permanecer aseguró a sus habitantes ciertos servicios sanitarios básicos, siendo de esta forma una amenaza más al estado nigeriano ${ }^{23}$. ISWAP ha hecho base en algunas islas del lago Chad.

21 Por ejemplo, la ciudad pescadora de Baga en las orillas del lago Chad, estuvo seis semanas ocupada por Boko Haram durante las cuales asesinaron a más de 2000 personas, casi todos hombres jóvenes, y obligaron al matrimonio forzoso con integrantes del grupo a decenas de mujeres jóvenes solteras (The New Humanitarian, 2019)

22 El ejército nigeriano obligó en múltiples ocasiones el abandono de hogares y el desplazamiento forzoso de sus habitantes sobre todo en la región de Borno. "Estos flagrantes actos en los que se han arrasado aldeas enteras, se han destruido deliberadamente viviendas civiles y se ha desplazado por la fuerza a sus habitantes sin que hubiera razones militares imperativas deben ser investigados como posibles crímenes de guerra", dijo Osai Ojigho, directora de Amnistía Internacional Nigeria (Amnistía Internacional, 2020). El Gobierno de Chad tuvo actitudes similares para con los pobladores de las islas del lago en su territorio. En julio de 2017, el ejército chadiano ordenó la evacuación de todas las islas notificando a sus habitantes que de no hacerlo sería considerados como miembros de Boko Haram.Alrededor de quince mil isleños abandonaron las islas (The Yorker, 2017).

23 Esto no significa de manera alguna que no haya recurrido a secuestros extorsivos para presionar al Estado nigeriano, como los realizados en la ciudad de Nur, ni que avance en forma pacífica. 
La respuesta militar de los estados se canalizó a partir de la Fuerza Multilateral Conjunta ${ }^{24}$ (FMC) y de diversas operaciones nacionales o bilaterales en los diversos estados afectados ${ }^{25}$. La FMC organizó varias operaciones resonantes ${ }^{26}$ algunas con éxito y otras no tanto, pero logró reducir notablemente el área de influencia de Boko Haram, que hacia 2015 había llegado a ocupar casi por completo el estado de Borno en Nigeria, parte de la Provincia Norte de Camerún y la cuenca del lago Chad.También se enfrentó a ISWAP ${ }^{27}$. Los enfrentamientos con los grupos terroristas han dejado más de 35.000 muertos y dos millones de desplazados (The New Humanitarian, 2019).

En la actualidad, Boko Haram se encuentra reducido a la cuenca del lago, donde tiene un centenar de pueblos bajo su poder. Está aún lejos de ser vencido; así lo demuestran los recientes ataques de marzo de este año contra las tropas nigerinas y chadianas que costaron más de un centenar de muertos ${ }^{28}$.

Tal como sucedió en otras regiones afectadas por la violencia terrorista, en la región del lago surgieron grupos de autodefensa locales, algunos organizados espontáneamente y otros alentados por las autoridades. Es el caso de la Fuerza Civil Conjunta de Nigeria o de la Hermandad de los cazadores (nkuradaji), en Camerún. En Níger, también se organizaron Comités de Paz, integrados por población comunitaria, hombres de negocios y religiosos.

Este conflicto tiene un componente adicional. Los enfrentamientos entre ganaderos y agricultores, $y$ el terrorismo asociado a un islam violento y militante reforzaron las identidades religiosas ahondando las diferencias entre las diversas poblaciones. En el caso de los enfrentamientos comunales, los pastores son mayoritariamente musulmanes mientras que las poblaciones sedentarias son principalmente cristianas; el terrorismo profesa el islam. La situación favorece la construcción de estereotipos de unos y otros que hacen proliferar tanto teorías conspirativas como acciones violentas únicamente por cuestiones religiosas. Las poblaciones sedentarias acusan a los pastores fula musulmanes de poseer un plan a largo plazo para quitarles sus tierras mientras que otros grupos también cristianos aseguran que esto forma parte de un plan para islamizar el país (ICG, 20I7, pp. 8-9). Por su parte, los speeches mediáticos violentos del líder de Boko Haram, Abubakar Shekau, utilizando el islam para sustentar sus amenazas o reivindicaciones violentas, no hizo más que colaborar para ahondar los clivajes religiosos en este contexto conflictivo.

24 La Fuerza Multilateral Conjunta (FMC) surgió originariamente en 1994, por iniciativa de la Comisión de la Cuenca del Chad, para brindar seguridad contra el bandidismo y asegurar la libertad de movimiento de sus habitantes. Fue revitalizada en 2014 para la lucha contra los grupos terroristas trasnacionales que amenazaban a los estados de la cuenca. Integrada por los estados de Nigeria, Níger, Camerún y Chad (y la participación no muy clara de Benín), su cuartel general se encuentra en Yamena y su comandante en jefe es nigeriano, por pedido expreso del actual presidente Muhammadu Buhari; el peso militar, más allá de la cantidad de soldados nigerianos y de su importante aporte económico, recae sobre las tropas de Chad por su formación y su capacidad estratégica, visiblemente mejorada por Francia. La Fuerza Multinacional Conjunta está reconocida por la Unión Africana y Naciones Unidas.

25 Las operaciones en territorio nigeriano bajo la presidencia de Goodluck Jonathan fueron especialmente violentas y en múltiples ocasiones no discriminó entre civiles y terroristas. Hasta llegó a organizar verdaderos escuadrones de la muerte que aterrorizaron a la población civil de regiones completas.

26 Como por ejemplo la operación Gama Aiki (junio de 2016) seguida de la operación Rawan Kada, ambas en la zona del lago Chad (OmarNdubuisi, 2018, p. II).

27 Además de las operaciones llevadas a cabo por la FMC hubo iniciativas bilaterales encaradas por Nigeria y Camerún, por ejemplo, la Operación Ngoshe y la Operación Deep Punch 2. La Operación Last Hold fue llevada a cabo por las fuerzas nacionales de Nigeria en la región de este país correspondiente del Lago Chad, en 20I8, sobre todo contra ISWAP (Omar-Ndubuisi, 20I8, PP. II - I4).

28 Boko Haram llevó a cabo mortíferos ataques contra tropas nigerianas y de Chad durante el mes de marzo de 2020 que costaron más de 170 militares muertos. Como represalia, el ejército chadiano respondió con un ataque militar a principios de abril que costó muchas bajas al grupo terrorista. 


\section{Conclusiones}

Las posibilidades de acceso al agua hacen que la región del lago Chad sea una vía de escape para todos aquellos perjudicados por políticas estatales, conflictos armados o procesos de desertización. En este sentido, el lago es una caja de resonancia de lo que ocurre fuera de la cuenca pero también una muestra de las geometrías de poder, de las políticas implementadas en torno a problemas de larga data y de las relaciones socioculturales y económicas de los estados que comparten la cuenca. Como tal es un problema complejo que requiere respuestas multidimensionales pues es un problema multidimensional.

La violencia estatal, comunal y terrorista es producto de una combinación de factores que incluye la desertización pero no es ésta su única causa. El abandono y el patrimonialismo del estado ha favorecido, por un lado, la desconfianza de los habitantes de las regiones desérticas y semidesérticas y por otro, la instalación de grupos terroristas que en ocasiones han ocupado su lugar.

La situación del lago Chad, como la de las regiones desérticas de los estados que componen su cuenca, pone de manifiesto cómo las poblaciones que viven de la ganadería necesitan ser incluidas en un esquema de usufructo de la tierra y del acceso al agua que contemple su forma de vida semi nómada.

Según Médicos Sin Fronteras, en la región del lago Chad, cerca de 10 millones de personas necesitan ayuda humanitaria urgente para sobrevivir mientras que 17 millones se encuentran afectadas por la violencia. No sostenemos que esta situación pueda deberse únicamente al simple resultado de un proceso climático provocado por el cambio en el régimen de lluvias. Tal como sostiene Swyngedouw (2009, p. 58), que:

"El acceso inequitativo o el control del agua son invariablemente el resultado de las condiciones geográficas, las decisiones técnicas y las disposiciones político-legales, $y$ la inequidad en el acceso al agua debe entenderse cada vez más como el resultado de la interacción entre esos tres factores".

En tal sentido, la situación sanitaria se corresponde al waterscape que hemos analizado en estas páginas y que está atravesado por una combinación de factores y procesos que tienen al estado y a las comunidades como grandes protagonistas del problema y de las posibles soluciones.

En este sentido, las grandes obras que piensan implementarse - la Gran Barrera Verde y el Proyecto UNESCO 2018- per se no solucionarán la cuestión. Más allá del impacto que estas pudieran tener, es necesaria una transformación estructural dentro de la concepción del estado, de forma que signifique el abandono de las prácticas neopatrimoniales y que consecuentemente logre cambiar la relación con sus gobernados. Y esto debido a que las geometrías de poder y los actores sociales vinculados a las políticas que se implementen serán quienes finalmente podrán producir una transformación hidrosocial que asegure un acceso más equitativo al agua y que a su vez permita alcanzar la paz en la región. El cambio verdadero no lo aportará una variación climática, aunque esto podría colaborar en su empeoramiento. El cambio provendrá de la transformación del waterscape. Las obras... más que bienvenidas, pero no alcanzará sólo con ello. 


\section{Referencias}

ACAPS. (2I.3.20I7). Nigeria. Farmer-Fulani HerderViolence in Benue, Kaduna and Plateau State. Thematic Reports. Recuperado de: https://reliefweb.int/report/nigeria/nigeria-farmer-fulani-herder-violence-benue-kaduna-and-plateau-states-thematic-report [Última consulta: 23.03.2020].

International Crisis Group (ICG). (19.9.20I7) Herders against Farmers: Nigeria's Expanding Deadly Conflict.Africa Report $N^{\circ}$ 252. Recuperado de: https://www.crisisgroup.org/africa/west-africa/nigeria/252-herders-against-farmersnigerias-expanding-deadly-conflict [Última consulta: 23.03.2020].

International Crisis Group (ICG). (26.9.20I8) Stopping Nigeria's Spiralling Farmer-HerderViolence. Africa Report $N^{\circ} 262$ Recuperado de: https://www.crisisgroup.org/africa/west-africa/nigeria/262-stopping-nigerias-spiralling-farmer-herder-violence [Última consulta: 23.03.2020].

Ki-Zerbo, J., Mazrui, A. y Wondji, C. (1993). Nation Building and changing political values. En: Mazrui, A. (Dir.). General History of Africa VIII - Africa since 1935. Berkeley: University California Press.

Larsimon, Robin. (20I4) Ecología política del agua: reflexiones teórico-metodológicas para el estudio del regadío en la provincia de Mendoza.Trabajo presentado en: $2^{\circ}$ Encuentro de Investigadores en Formación en Recursos Hídricos, Buenos Aires.

Lemoalle, J. (20।4). “Le fonctionnement hydrologique du lac Tchad”. En: Lemoalle J., Magrin G. (Dir.). Le développement du lac Tchad: situation actuelle et futurs possibles (pp. I-58). Marsella: IRD Editions.

Mahmood, O. y Ani, N. (2018) Responses to Boko Haram in the Lake Chad Region: Policies, Cooperation and Livelihoods. En: ISS RESEARCH REPORT. Recuperado de : https://issafrica.org/research/books-and-other-publications/ responses-to-boko-haram-in-the-lake-chad-region-policies-cooperation-and-livelihoods [Última consulta: 29.02.2020].

Molle, François. (20I2). La gestion de l'eau et les apports d'une approche par la political ecology. En : Gautier, D y Benjaminsen, A.T. (Dir.) L'approche Political Ecology: Pouvoir, savoir, environnement (pp. 21 9-240). Paris: Quae.

Moritz, Mark. (2005). FulBe Pastoralists and the Neo-Patrimonial State in the Chad Basin. Geography Research Forum, 25, pp. 83-I04. DOI: 10.5876/978I607323433.c007.

MSF. (2018) Lake Chad Crisis. Over 10 million people heavily dependent on aid for survival. Recuperado de: https://www. msf.org/lake-chad-crisis-depth [Última consulta: 28.2.2020].

Réounodji F., Sylvestre, F., Saibou I., Rangé C. y Amadou, B. (2014). Histoire du peuplement et logiques de mobilité. En: Lemoalle, J. y Magrin, G. (Dir.): Le développement du lac Tchad. Situation actuelle et futurs possibles (pp. 139- I77). Marsella: IRD Editions.

Swyngdouw, E. (2009). The political economy and political ecology of the hidrosocial Cycle. Journal of Contemporary Water Research \& Education, I42, 56-60. DOI: I0.1 I I I/j.1936-704X.2009.00054.x

The New Humanitarian. (06.08.2019) Reporter's Diary: Boko Haram and the battle of ideas. A decade of war, and Nigeria's jihadists still pose an ideological challenge. Recuperado de: https://www.thenewhumanitarian.org/analysis/2019/08/06/Nigeria-boko-haram-ISWAP-and-battle-ideas-Lake-Chad [Última consulta: 25.03.2020].

The Yorker. (2017) Lake Chad:The World's Most Complex Humanitarian Disaster. Recuperado de:

https://www.newyorker.com/magazine/2017//2/04/lake-chad-the-worlds-most-complex-humanitarian-disaster [Última consulta: 19.04.2020]. 


\section{RELACIONES INTERNACIONALES}

Revista académica cuatrimestral de publicación electrónica

Grupo de Estudios de Relaciones Internacionales (GERI)

Universidad Autónoma de Madrid, España

https://revistas.uam.es/relacionesinternacionales

ISSN 1699 - 3950

f facebook.com/RelacionesInternacionales

3. twitter.com/RRInternacional 